\title{
Cross-Cultural Dimensions and Financial Efficiency: An Investigation at Macro Level
}

\author{
Zixue Zhao ${ }^{1, *}$ \\ ${ }^{1}$ School of Statistics and Mathematics, Yunnan University of Finance and Economics, Kunming, Yunnan, China \\ *Corresponding author. Email: nana0000@foxmail.com
}

\begin{abstract}
Based on the four cultural dimensions summarized by Hofstede's research team, this paper divides financial efficiency into direct financial efficiency and indirect financial efficiency, so as to study the influence of culture on financial efficiency and the relationship between the two. This paper finds that the correlation between different cultural dimensions and financial efficiency is significantly different. The correlation test proves that only power distance and individualism are significantly correlated with financial efficiency. Regression analysis supports that only individualism is significantly related with financial efficiency after adding three control variables, in which individualism index is negative with indirect financial efficiency, and positive with direct financial efficiency. In addition, the correlation between individualism and financial efficiency varies depending on whether the country is a developed one or not.
\end{abstract}

\section{Keywords: cultural dimensions, financial efficiency, multi-level linear regression}

\section{INTRODUCTION}

Financial development, as an important content of modern financial economics, is more and more popular with scholars. As increasing concerns on financial theory and practical finance, especially since the global wide economic and financial crisis in recent years, the academic world is urgent to find out more regularities of financial development from the view of people's social attributes. Ben (2011) suggested that culture is maybe the most significant factor to explain the huge financial difference between individuals and nations, and the cultural characteristics are the key to this problem. Linking culture traits with financial activities have been a popular topic and domain goals in further studies in cultural economics.

Accordingly, clarifying the effect of culture on financial development will contribute to a more comprehensive aspect on understanding the influence of people's social attributes on economic activities. As a typical interdisciplinary research, it also aims to broaden the study area of behavioral finance and cultural economics.

The existed literature with related topics generally starts from three perspectives: cultural variables, cultural distance and cultural dimension. Taking into account the fact that different cultural characteristics has different impacts on financial activities, this paper chooses an entry point of the macro level; matches the Hofstede's cultural dimension theory, which is an important indicator of cultural characteristics. In the aspect of financial development, this paper chooses financial efficiency as the index of judgment. More explanations will be demonstrated to following part. Lastly, quantitative analysis will be applied.

\section{CULTURAL AND FINANCIAL EFFICIENCY}

Financial efficiency is a macro-level concept, which refers to how the financial sector of a country balances the relationship between input and output in the financial market and financial products. It is also a kind of financial organizational capacity (Sudha, 1989) and also refers to the investment efficiency of individuals or enterprises. Therefore, financial efficiency is a comprehensive indicator, and its measurement method is not fixed.

According to different financial entities, financial efficiency is generally divided into macro, micro and market efficiency. The macro-financial efficiency corresponds to the efficiency of national financial intermediaries and financial markets, which is the ratio of policies and economic achievements. Micro-financial efficiency represents the profitability of financial institutions or individuals. Financial market efficiency represents the ratio of input to output in the securities market. Because it refers to the security market, the micro financial efficiency cannot reflect the difference between the collective level. Therefore, the financial efficiency in this paper refers to the macro-financial efficiency. 
Tadesse \& White (2010) provided a basic theory which aims at the correlation between culture differences and financial development. In essence, at the individual level, the cultural characteristics of micro individuals will affect their financial preference and expectation of the decision-making. This cultural characteristic reflects their belief, religion and trust. At the collective level, the cultural values of regional level are one of the significant tasks for financial efficiency or financial operation. It refers to different cultural dimensions. Based on this theory, we could examine the correlation between multi-cultural dimensions and financial efficiency. ("Fig. 1")

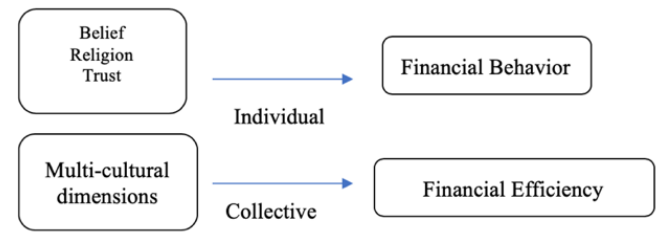

Fig. 1. Cultural, financial behavior and financial efficiency.

\section{MULTI-DimenSIONAL CULTURAL DIFFERENCES AND FINANCIAL EFFICIENCY}

Countries with higher score of uncertainty avoidance preferred financial intermediaries (banks) over financial markets (securities market). The reason is that the greater the uncertainty aversion in a society, the less people are prepared to take risks, and the less they trust incomplete contracts, such as stocks. Since bank funds to require collateral, and banks have established a relationship of mutual trust in their long-term cooperation with customers, countries with insufficient social trust and social capital are more likely to support a financing system dominated by banks rather than financial markets.

In terms of corporate finance, Aggarwal (1981), after analyzing the 500 largest European companies, believed that national culture is a significant factor of capital structure. The research conclusion of Chui, Lioyd and Kwok (2002) also supported this view. They explored the data samples of 4981 enterprises in 25 countries. After empirical analysis with financial models and psychology theory, they found that countries with a strong "conservative" culture to value to tend to have a lower corporate debt ratio. The results were significant even when adding control variables for economic performance, GDP, financial markets, education system and others. Chang (2009) found that the three dimensions - - uncertainty avoidance, masculinity and long-term orientation were significantly positively correlated with corporate cash holdings.

Other findings: countries with high power distance, authority and autocracy are more likely to happen, which may lead opportunists to seek personal gain and reduce the efficiency of economic cooperation (Dow, 1987; John, 1984). According to the research of Ghoul, Guedhami and Kwok (2012), managers in highmasculinity countries are more likely to show a wide range of risk preference behaviors, which is called overinvestment. At the same time, they found that countries with high levels of uncertainty aversion, creditors sought to avoid future uncertainty, preferring to issue short-term debt and seek low-risk portfolios.

\section{MEASUREMENT}

\section{A. Cultural dimension variables}

Based on Hofstede's cultural dimension theory, this paper selected the latest panel data according to Hofstede's home page (http://geert-hofstede.com/). Due to the data deficiencies in last two cultural dimensions: "long-term orientation vs. short-term orientation" and "indulgence vs. constraint", only 4 cultural dimensions and the effective data provided by Hofstede's group including 68 countries and are taken.

\section{B. Financial variables}

This paper studies on the macro-financial efficiency. Relate researchers often use the amount of financial credit, such as the amount of deposits (Maying et al., 2009), the amount of loans or the ratio between the amount of loans at the end of the year (Shenglin, 2011) and the amount of deposits at the end of the year, to represent it. Chui et al. (2010) proposed that since the macro-financial efficiency of a country should be comprehensively considered from the perspectives of financial intermediation and financial market, two indicators could be used: the bank's net interest margin and the turnover rate of stock transactions, which can evaluate the financial development efficiency of each country from the perspective of indirect financial efficiency and direct financial efficiency respectively.

Bank net interest margin represents the ratio of the bank's net interest income to the bank's total interestearning assets. Essentially, it reflects the loaning status and financing level of a country's citizens in intermediary financial institutions such as commercial banks. A high bank net interest margin represents a higher interest rate on the bank's income under the condition of the same assets. In other words, investors are more willing to absorb deposits from the society through banks, which is also called credit financing. The higher the bank's net interest margin, the higher the efficiency of indirect financing.

Stock market turnover ratio represents a kind of direct financing, which means the state or companies raise funds directly from the market instead of intermediaries, such as issuing stocks or bonds. The higher the stock market turnover ratio, the higher the 
efficiency of direct financing. Indirect financing efficiency and direct financing efficiency have a substitution relationship to some extent.

In combination with the relevant data onto cultural dimension variables obtained, I selected cross-sectional data (year: 2015) for both variables. Database: world development indicators (WDI).

\section{Control variables}

Due to the close correlation between financial activities and other economic and cultural activities, this study will also control the following variables: GDP per capita, secondary school enrollment rate, and economic freedom summary index.

\section{HYPOTHESIS}

\section{A. Individualism}

Markus and Kitayama (1991) found through their research on the stock market that countries with a higher tendency of individualism were more likely to develop "overconfidence" in the stock market, that is, in direct financing. Individualists emphasize individual differences and are more "confident" in raising funds directly in the stock market and obtaining higher return opportunities than those who carefully borrow from banks. By empirical research, Fidrmuc \& Jacob (2010) also believed that the higher the score of individualism, the more actively the country would participate in the stock financing. As a result, the turnover rate of stock trading is higher.

On the other hand, Licht et al. (1995) believed that countries with lower individualism and higher collectivism would have higher social and economic equity. People in countries with collectivist cultures are less likely to engage in opportunistic behaviors (Hofstede, 1984), so they are less likely to participate in arbitrage and speculation in the stock market. In order to ensure that they are part of the group, collectivists will choose bank financing with lower risk, lower threshold and generally preferred by most people, leading to higher indirect financial efficiency, namely higher bank net interest margin. The empirical analysis of Aggarwal and Goodell (2009) also supports this view. They argue that collectivist countries are more likely to support a bank-dominated financial system.

H1a: Individualism index is negatively related with bank net interest margin.

$\mathrm{H} 1 \mathrm{~b}$ : Individualism index is positively related with stock market turnover ratio.

\section{B. Uncertainty avoidance}

Chang \& Noorbakhsh (2009) found that the higher the uncertainty avoidance, the higher the cash holdings of the country or the enterprise. The large amount of cash holdings represents that the main source of financing for relevant institutions are indirect financing, rather than bonds. One explanation is that countries with higher levels of uncertainty avoidance have financiers who fear the unknown things; they do not seek diversification, lack of innovation. Bank borrowing is a relatively stable and controllable financing activity. At the same time, people with a high degree of uncertainty avoidance emphasize professionalism, preferring to trust traditional banks of the bewildering mix of bonds and stocks on the stock market. Thirdly, the procedures of indirect financing are more rapid and convenient than direct financing, and the additional transaction costs and uncertain risks may be less in the process of operation. Therefore, the higher the uncertainty aversion, the more likely the country is to support the indirect financial system dominated by banks, rather than the direct financial system dominated by stocks and bonds. It is less risky and more suitable for countries with a high degree of uncertainty avoidance.

Besides, in countries with low uncertainty avoidance, people do not feel strongly uncomfortable about taking risks (Steenkamp et al., 1999). The cost of direct financing, which are dominated by stocks and bonds, are higher than indirect way. In order to attract idle funds from the society, the interest rate of bonds and stocks is usually higher than the interest rate of bank deposits at the same time. As a result, the interest paid by direct financing is higher and the operating risk is higher. Cultures with low uncertainty avoidance are more capable of bearing associated risks.

$\mathrm{H} 2 \mathrm{a}$ : Uncertainty avoidance index is positively related with bank net interest margin.

$\mathrm{H} 2 \mathrm{~b}$ : Uncertainty avoidance index is negatively related with stock market turnover ratio.

\section{Power distance}

Fidrmuc \& Jacob (2010) believed that the higher power distance index is, the lower the dividend distribution. This is consistent with his analysis of individualism. High power distance represents more unequal to the society. Within society there is more emphasis on maintaining the status quo. Therefore, in countries with high power distance, people will not deliberately pursue independence. As an emerging financing means, bond and equity financing will not easily break the status quo to pursue higher-end financing means. Secondly, people in countries with high power distance will follow centralized command and management (Johne, 1984), so simple and quick instructions and operations are more efficient. The services offered by banks are relatively simple and convenient, requiring no individual thinking, which fit with people in high power distant countries accustomed 
to following orders. Therefore, countries with a high power distance will prefer indirect financing represented by banks, so the net interest margin of banks will be higher.

On the contrary, countries with low power distance are less concerned about hierarchy and more willing to seek diversity (Doepkes \& Zilibotti, 2013). There are more diversified options of direct financing and the benefits of diversification. There are many channels for direct financing to absorb funds, which can better to meet people's different needs. Secondly, there is a high degree of trust among people and a high level of cooperation (Neal, 1990). This leads to opportunities for people to share information or participate in decision-making. Therefore, the general quality and level of investors participating in the financial market will be higher. This meets the requirements for direct financing -- having sufficient information and capacity. As a result, countries with low power distances are more efficient at direct financing.

$\mathrm{H} 3 \mathrm{a}$ : Power distance index is positively related with bank net interest margin.

H3b: Power distance index is negatively related with stock market turnover ratio.

\section{Masculinity}

Ron et al. (2011) believes that countries with high degree of masculinity are more inclined to engage in direct financing, that is, stock or bond financing. Countries with higher degree of femininity tend to engage in indirect financing, that is, bank financing. Because in cultures dominated by masculinity, people pursue success and emphasize the accumulation of wealth (Demoojj \& Hofstede, 2002). Therefore, in this environment, investors will value returns more. Moreover, the stock or the bond financing will not be restricted by the policy, may obtain the large-scale capital at a time, and the long-term flexible use. The financing amount of direct financing is generally higher than that of indirect financing. Countries with high masculinity will actively pursue securities market financing such as stocks with higher monetary returns, so the turnover ratio in the stock market will be higher.

In contrast, feminine-dominated cultures care less about money and status and more about team harmony and internal acceptance. The indirect financing provided by the bank have many restrictive clauses on the use of funds by the financier, such as the limitation on the use of funds, which is more suitable for the prudent population. In addition, bank financing to require property guarantees or third-party guarantee. Countries dominated by femininity are more inclined to cooperate and have more partners, so it is easier to obtain third-party guarantee and obtain bank financing. Finally, countries with high femininity score emphasize low profile and low visibility, and the bank financing process is more private. Therefore, countries with a high femininity score are more likely to choose indirect financing, resulting in higher bank net interest margin.

$\mathrm{H} 4 \mathrm{a}$ : Masculinity index is negatively related with bank net interest margin.

H4b: Masculinity index is positively related with stock market turnover ratio.

\section{Method}

Based on above assumptions and collected data, this paper adopts a quantitative method of data analysis. First, this paper carries out correlation analysis on all independent variables, dependent variables and control variables. Look for relationships between variables to prepare for the next step of the regression analysis.

After that, a simple linear regression model is used in this paper. The two dependent variables were modeled separately to investigate the influence of independent variables and control variables on the two dependent variables. The regression models are as follows:

$$
\begin{aligned}
& N I M=\alpha_{1} P D I+\beta_{1} I D V+\gamma_{1} M A S+\delta_{1} U A I+ \\
& \mu_{1} G D P+\rho_{1} \text { School }+\sigma_{1} E F I+\varepsilon 1 \\
& S M T=\alpha_{2} P D I+\beta_{2} I D V+\gamma_{2} M A S+\delta_{2} U A I+ \\
& \mu_{2} G D P+\rho_{2} \text { School }+\sigma_{2} E F I+\varepsilon 2
\end{aligned}
$$


Finally, based on the results of correlation analysis and simple linear regression, this paper continues to use multi-level linear regression for multi-level analysis.

$$
\begin{aligned}
& N I M^{s}=\alpha_{11} P D I+\beta_{11} I D V+\gamma_{11} M A S+\delta_{11} U A I+ \\
& (1 \mid \text { Status })+\varepsilon_{1} \\
& S M T^{s}=\alpha_{21} P D I+\beta_{21} I D V+\gamma_{21} M A S+\delta_{21} U A I+ \\
& (1 \mid \text { Status })+\varepsilon_{4}
\end{aligned}
$$

\section{RESUlts}

\section{A. Correlation analysis}

As can be observed from the correlation matrix "Table I", first of all, among the four independent variables, there is a strong negative correlation between power distance and individualism, with the correlation coefficient reaching -0.634 . This means that the higher the power distance index, the lower the individualism index. Obviously, countries with high power distance
Prepare for further research in the future. The multilevel linear regression models are as follow:

TABLE I. CORRELATION MATRIX OF ALL VARIABLES

\begin{tabular}{lrrrrrrrrr}
\hline & $P D I$ & \multicolumn{1}{c}{ IDV } & MAS & UAI & NIM & SMT & GDP & School & EFI \\
\hline PDI & 1.000 & & & & & & & & \\
IDV & -0.634 & 1.000 & & & & & & & \\
MAS & 0.160 & 0.051 & 1.000 & & & & & & \\
UAI & 0.209 & -0.221 & -0.048 & 1.000 & & & & & \\
Bank net interest margin & 0.329 & -0.530 & 0.171 & 0.049 & 1.000 & & & & \\
Stock market turnover ratio & -0.086 & 0.357 & 0.152 & -0.164 & -0.195 & 1.000 & & & \\
GDP per capita & -0.616 & 0.630 & -0.013 & -0.295 & -0.530 & 0.123 & 1.000 & & \\
School enrollment, & & & & & & & & & \\
secondary & -0.488 & 0.561 & -0.267 & -0.092 & -0.420 & 0.217 & 0.499 & 1.000 & \\
Economic Freedom Index & -0.339 & 0.445 & -0.123 & -0.203 & -0.528 & -0.026 & 0.594 & 0.320 & 1.000 \\
\hline
\end{tabular}

Second, by observing the two dependent variables, we can draw a simple conclusion: basically, NIM and SMT are substitutive to some extent. Their correlation coefficient was -0.195 .

Third, bank net interest margin is positively correlated with power distance, negatively related with individualism, positively related to masculinity, and positively related with uncertainty avoidance. The correlation to individualism is the strongest, and that with uncertainty avoidance is the weakest. This means that the more individualistic a country is, the less willing people are to finance through banks, and the lower Bank net interest margin will be. The higher the power distance and uncertainty avoidance, the more willing people are to finance indirectly through Banks. These are all consistent with our previous assumptions. However, the relationship between masculinity and NIM is not what we expected. We can continue to judge the reference value of these data results from the subsequent regression analysis. On the other hand, the SMT is negatively correlated with power distance, positively related with individualism, positively related with masculinity and negatively related with uncertainty avoidance, respectively.

Fourth, the correlation coefficient of NIM and the three control variables is close to -0.5 . Furthermore, the correlation coefficient of power distance, individualism index and three control variables are also within the range of $0.4 \sim 0.6$, especially the correlation coefficient with GDP per capita is above 0.6. It is reasonable to believe that the influence of power distance and individualism on bank net interest margin may vary according to the change of control variables, especially to GDP per capita. However, the effect of control variables to stock market turnover ratio may not that significant based on the correlation matrix.

\section{B. Simple linear regression}

"Table II" shows the influence of other independent variables and control variables on NIM and SMT when they are taken as dependent variables respectively. The left part of table 2 show that when all variables are 
combined, only individualism and GDP per capita are statistically significant at the 5\% level. According to the standardized coefficient, we can observe that individualism has the biggest impact on NIM, followed by GDP per capita, power distance and masculinity. Secondly, the $\mathrm{R}$ square of this regression model is 0.436 , which means that all these variables can provide a total of $43.6 \%$ explanations for the change of NIM, and $56.4 \%$ of the reasons are not included.

The right part of "Table II" show that when all variables comprehensively explain the stock market turnover ratio, only the individualism index is statistically significant at the level of $5 \%$. According to the standard coefficient, it can be observed that individualism still has the largest impact on the stock market turnover ratio, and it is a positive impact contrary to the impact on bank net interest margin. Second, the R square of this regression model is 0.199, which means that all these variables together can account for nearly $20 \%$ of changes in bank net interest margin.

To sum up, individualism has a greater direct and indirect impact on financial efficiency than other cultural dimensions. In addition, GDP per capita has a significant impact on indirect financial efficiency. In the subsequent multi-level regression analysis, we will use GDP per capita as the stratification standard and consider the impact of four dimensions on financial efficiency in different level of GDP per capita.

TABLE II. SIMPLE LINEAR REGRESSION MODEL

\begin{tabular}{|c|c|c|c|c|c|c|c|c|}
\hline \multirow{3}{*}{$\frac{\text { Predictors }}{\text { (Intercept) }}$} & \multicolumn{4}{|c|}{ NIM } & \multicolumn{4}{|c|}{ SMT } \\
\hline & \multicolumn{2}{|c|}{ Estimatesstd. Beta } & \multirow{2}{*}{$\frac{C I}{3.53-14.97}$} & \multirow{2}{*}{$\begin{array}{c}\text { standardized } C l \\
-0.21-0.21\end{array}$} & \multicolumn{2}{|c|}{ Estimates std. Beta } & \multirow{2}{*}{$\frac{C I}{-110.14-144.25}$} & \multirow{2}{*}{$\frac{\text { standardized } C I}{-0.27-0.27}$} \\
\hline & $9.25^{* *}$ & 0.00 & & & 17.06 & -0.00 & & \\
\hline PDI & -0.02 & -0.22 & $-0.04-0.01$ & $-0.52-0.08$ & 0.18 & 0.13 & $-0.37-0.73$ & $-0.27-0.54$ \\
\hline IDV & $-0.04^{*}$ & -0.45 & $-0.06--0.01$ & $-0.79--0.11$ & $0.56^{\circ}$ & 0.44 & $0.01-1.12$ & $0.01-0.88$ \\
\hline MAS & 0.02 & 0.21 & $-0.00-0.04$ & $-0.02-0.44$ & 0.17 & 0.11 & $-0.29-0.62$ & $-0.19-0.42$ \\
\hline UAI & -0.02 & -0.18 & $-0.04-0.00$ & $-0.41-0.05$ & -0.07 & -0.05 & $-0.50-0.35$ & $-0.37-0.27$ \\
\hline GDP & $-0.00^{*}$ & -0.33 & $-0.00--0.00$ & $-0.66--0.00$ & -0.00 & -0.01 & $-0.00-0.00$ & $-0.44-0.42$ \\
\hline School & -0.00 & -0.02 & $-0.03-0.02$ & $-0.30-0.26$ & 0.15 & 0.10 & $-0.40-0.69$ & $-0.28-0.48$ \\
\hline EFI & -0.38 & -0.15 & $-1.06-0.29$ & $-0.40-0.11$ & -5.32 & -0.12 & $-19.41-8.77$ & $-0.45-0.20$ \\
\hline Observations & 61 & & & & 51 & & & \\
\hline $\mathrm{R}^{2} / \mathrm{R}^{2}$ adjusted & $0.436 / 0.3$ & & & & $0.199 / 0$. & .069 & & \\
\hline
\end{tabular}

\section{Multi-level linear regression}

According to the results of the simple linear regression model above, we eliminated the secondary school enrollment rate and economic freedom index, and only retained the basic four cultural dimensions as independent variables. Meanwhile, GDP per capita is used to judge the random effect on different GDP levels. Since the most important criterion to judge developed and developing countries is GDP per capita, this paper uses the labels of developed and developing countries to represent different GDP per capita levels in this model and adds a new factor variable: Status. More details can be referred to the regression formula described in the Method section above.

"Table III" illustrates the most independent variables in the fixed effect are not statistically significant, except individualism and masculinity. According to the conclusion of previous studies, individualism is the most important factor affecting NIM and SMT, and the new regression model still supports this conclusion. In the random effect part, Marginal R square represents the interpretation level of fixed effect, that is, fixed effect can explain $17.8 \%$ and $13.2 \%$ dependent variables. Conditional $\mathrm{R}$ square represents the interpretation level of the model after the addition of random effect. You can see that the interpretation level of the model increased to $33.9 \%$ and $16.4 \%$ after taking into account whether the countries were developed or not. The $\sigma^{2}$ represents the variance;

$\tau_{00}$ tells that the whole model shift after adding random

effect, that means intercept is changed. In order to see the random effect more intuitively, this paper makes the following group of diagrams on the influence of each independent variable on the dependent variable according to different status (developing/developed): 
TABLE III. FIXED AND RANDOM EFFECTS

\begin{tabular}{|c|c|c|c|c|}
\hline \multirow[b]{2}{*}{ Predictors } & \multicolumn{2}{|c|}{ NIM } & \multicolumn{2}{|r|}{ SMT } \\
\hline & Estimates & $C I$ & Estimates & $C I$ \\
\hline (Intercept) & $4.02^{* *}$ & $1.31-6.74$ & -7.28 & $-60.68-46.12$ \\
\hline UAI & -0.00 & $-0.02-0.01$ & -0.09 & $-0.48-0.30$ \\
\hline MAS & $0.02^{*}$ & $0.00-0.04$ & 0.17 & $-0.27-0.60$ \\
\hline PDI & -0.01 & $-0.03-0.01$ & 0.27 & $-0.23-0.77$ \\
\hline IDV & $-0.04^{* *}$ & $-0.06--0.01$ & $0.54^{*}$ & $0.06-1.02$ \\
\hline \multicolumn{5}{|l|}{ Random Effects } \\
\hline$\sigma^{2}$ & \multicolumn{2}{|l|}{2.57} & \multicolumn{2}{|l|}{959.27} \\
\hline$\tau_{00}$ & \multicolumn{2}{|l|}{0.62 Status } & \multicolumn{2}{|c|}{36.59 Status } \\
\hline ICC & \multicolumn{2}{|l|}{0.20} & \multicolumn{2}{|l|}{0.04} \\
\hline $\mathrm{N}$ & \multicolumn{2}{|l|}{2 Status } & \multicolumn{2}{|l|}{2 Status } \\
\hline Observations & \multicolumn{2}{|l|}{68} & \multicolumn{2}{|l|}{54} \\
\hline Marginal $\mathrm{R}^{2}$ / Conditional $\mathrm{R}^{2}$ & \multicolumn{2}{|c|}{$0.178 / 0.339$} & \multicolumn{2}{|c|}{$0.132 / 0.164$} \\
\hline
\end{tabular}

Figures in "Fig. 2" have same dependent variable in $y$-axis: bank net interest margin; x-axis are different from each independent variable. Basically, developing countries holds higher bank net interest margin. The trend on power distance, masculinity and uncertainty avoidance are keeping in consistent from both developed and developing countries, except individualism. Generally, a positive relation between individualism and bank interest margin is shown in developed countries, and a negative relation is shown in developing countries. It is quite significant to consider economic situation before exploring the influence of individualism on bank financing.
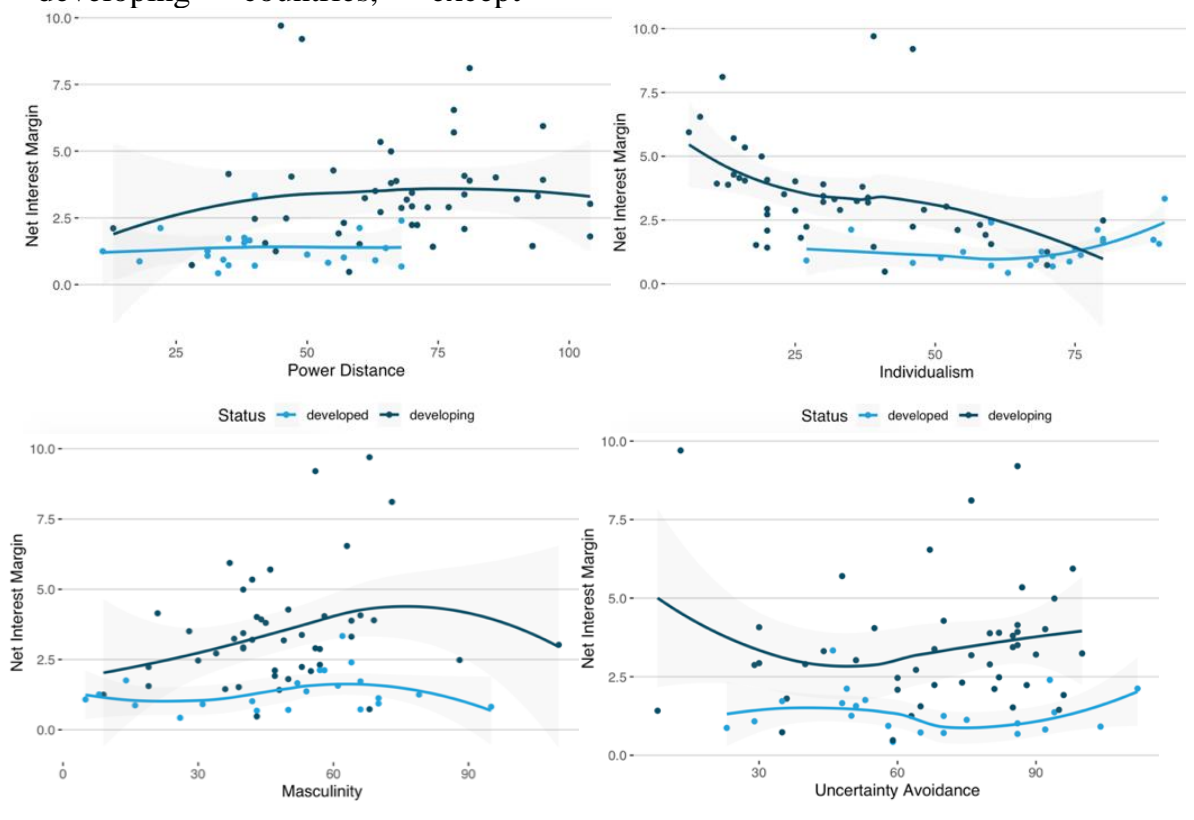

Fig. 2. Multi-level effect of each variables on NIM.

"Fig. 3" illustrates that generally developed countries have higher stock market turnover ratio. For power distance and masculinity, the waves are consistent with both developed and developing countries: go up first than keeping going down. For uncertainty avoidance, the effect is close to zero linear relation. However, it is noticed that the lines go in opposite directions in the first picture: the effect of 
individualism on STM in developed countries is $U$ shape; but it is averse-U shape in developing countries. It supports the results shown in the "Table III" that individualism is the most significant dimension in the model, and the effect may various by different GDP level.

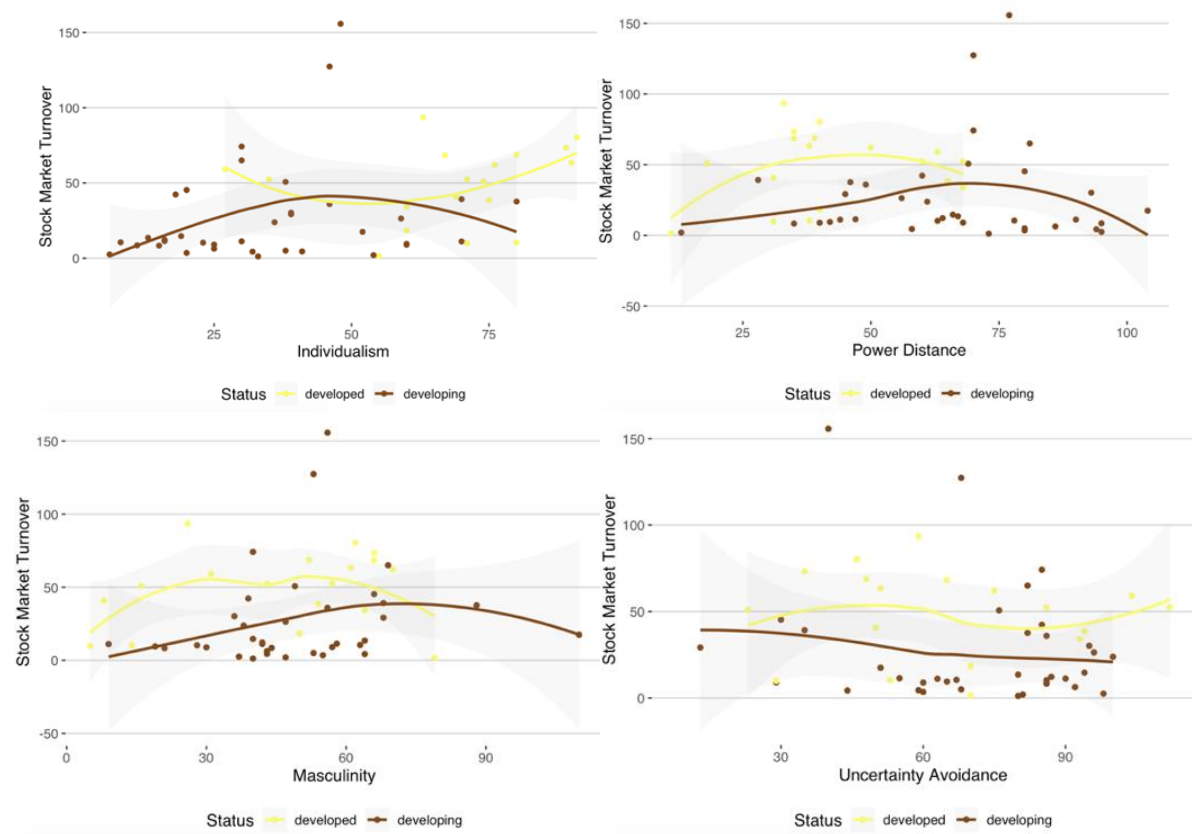

Fig. 3. Multi-level effect of each variables on SMT.

\section{CONCLUSION}

Generally, the regression results mainly support the significant effect of individualism to both indirect efficiency and direct efficiency. Precisely, individualism index is negative with indirect financial efficiency, and positive with direct financial efficiency. To other dimensions: power distance, masculinity, and uncertainty avoidance, the effect is not statistically significant.

Meanwhile, this effect may be influenced significantly by GDP per capita. GDP per capita could be considered as a moderator in the future study. What is more, the effect tends to be non-linear effect based on our models.

\section{References}

[1] Acemoglu,D., J.Robinson \& SJohnson. (2001).The Colonial Origins of Comparative Development: An Empirical Investigation. American Economic Review, 91(5), 1369-1401.

[2] Aggarwal, R., \& Goodell, J. W. (2009). Markets and institutions in financial intermediation: National characteristics as determinants. Journal of Banking \& Finance, 33(10), 17701780 .

[3] Chaney, E. (2013). Revolt on the Nile: Economic Shocks. Religion and Political Power. 81(5), 2033-2053.

[4] Chang, K., \& Noorbakhsh, A. (2009). Does national culture affect international corporate cash holdings? Journal of Multinational Financial Management, 19(5), 323-342.
[5] Chui, Titman and K.C.J.Wei.(2010). Individualism and Momentum around the World. The Journal of Finance,65(1), 361-392.

[6] Fidrmuc, J. P., \& Jacob, M. (2010). Culture, agency costs, and dividends. Journal of Comparative Economics, 38(3), 321-339.

[7] Francois, P., \& Zabojnik, J. (2005). Trust, social capital, and economic development. Journal of the European Economic Association, 3(1), 51-94.

[8] Greif,A. (1994). Cultural Beliefs and the Organization of Society: A Historical and Theoretical Reflection on Collectivis and Individualist Societies. Journal of Political Economy, 102(5), 912-950

[9] Guiso, L., P. Sapienza, L.Zingales.(2006). Does Culture Affect Economic Outcomes?. Journal of Economic Perspectives, 20(2), $23-48$.

[10] Hall, J.C. \& R.A. Lawson. (2014). Economic Freedom of the World: An Accounting of the Literature. Contemporary Economic Policy, 32(1), 1-19.

[11] Hausman, JA. \& W.Taylor.(1981). Panel Data and Unobservable Individual Effects. Econometrica, 49(6), 13771398.

[12] Hilary, G., \& Hui, K. W. (2009). Does religion matter in corporate decision making in America?. Journal of financial economics, 93(3), 455-

[13] Schwartz, S.H.(2007).Cultural and individual value correlates of capitalism.Psychological Inquiry, 18(1),52- 57.

[14] Wiliamson, O.E.(2000).The new institutional economics:Taking stock, looking ahead.Journal of Economic Literature, 38(3),595613. 